\title{
Gender Differences in Terms of Life Stressors in Adolescence
}

\author{
Lynette Da Silva Fortes ${ }^{1}$, Michelle Fernandes ${ }^{2}$ \\ ${ }^{1}$ Assistant Professor, Department of Psychology, Carmel College of Arts, Science and Commerce for \\ Women, Nuvem, Goa \\ ${ }^{2}$ Assistant Professor, Department of Psychology, Carmel College of Arts, Science and Commerce for \\ Women, Nuvem, Goa.
}

Corresponding author: Lynette Da Silva Fortes

Email-1ynt611@gmail.com

\begin{abstract}
Background: Adolescence denotes an eventful period, during which a growing individual makes the transition from a child to an adult. During adolescents there are forces that work against each other. There are conditions that push the youth forward and others that hold them back. A growing body of evidence points to the importance of life stressors and social resources in affecting adolescent functioning. This will help in the understanding the sources of stress and how they can cope with stress. The present study investigated gender differences in terms of life stressors of adolescents.

Methods: The total of 205 adolescents from South Goa, in the age range of 10 to 19 years, confining to World Health Organization standards as to the period of adolescence were the respondents to the questionnaires. In the attempt to study the extent of stress experienced by adolescents the Life Stressors and Social Resources Inventory (LISRES- Youth) and Mental Health Inventory (MHI-38) were used.

Results: Significant gender differences were obtained for the dimensions of school as a stressor and friends as a source of life stress, with male adolescents obtaining a higher score.

Conclusion: Gender differences in stress amongst adolescents needs further research and study.
\end{abstract}

Keywords: Adolescents, Gender differences, Life stressors, Negative Life Events.

(Paper received $-10^{\text {th }}$ April 2018, Peer review completed $-20^{\text {th }}$ May 2018)

(Accepted $-28^{\text {th }}$ May 2018)

\section{INTRODUCTION}

Adolescence is a time of significant developmental transition which results in numerous developmental challenges at varying pace, including: increasing need for independence; evolving sexuality; transitioning through education and beginning employment; consolidating advanced cognitive abilities; negotiating changing relationships with family, peers and broader social connections; assuming legal responsibilities; and developing personal ethics and a healthy identity [1]. The adolescent period is marked by increased involvement in risk behaviours. While these risk behaviours can predispose young people to poor long-term out comes, they are also seen as a normal part of adolescent development and are usually resolved by the beginning of adulthood [2].

While adolescence is a period of increased risk for problems, it also represents an important window of opportunity for change through intervention [3]. Behavioural changes that occur in the transition to adolescence maybe explained by the significant hormonal and physical changes (puberty) during adolescence as well as changes in brain function. 


\section{Stressors in Adolescence}

The situations and pressures as discussed above, that causes stress are known as stressors. Although S. Hall and others overdramatized the extent of "storm and stress" in adolescence, many adolescents today experience numerous potential stressors throughout the process of growth and development [4]. Stressors of both an acute and chronic nature are important in the course of normal development during adolescence. The types of stressors experienced in adolescence can broadly be divided into three categories. These categories are normative events, non-normative events and daily hassles [5]. Normative events refer to events that are experienced by most adolescents, but usually within a relatively predictable timescale. One important aspect here is that these are events which all young people have to confront, but usually within a relatively predictable timescale [5,6]. Non-normative events are different in the way that they are events affecting one adolescent or only a smaller group of adolescents and can occur at less predictable points in the life course [7]. Such events can include for example divorce, illness, injury or natural disasters.

Daily hassles differ from major life events in that they are defined as minor, irritating, and frustrating events that are typical of daily interactions between individuals and their environments. Even though these events are minor in scale, the sum and duration of these events may result in negative impact on adolescents' wellbeing [8]. Research has established that overall number of stressors tend to increase from preadolescence to adolescence. Girls tend to perceive higher levels of stress than boys, especially in relation to interpersonal stressors, e.g. peers, romantic partners, and family relationship [9-10].

\section{The Impact of Stress on Adolescence}

Although exposure to some stressful negative events is considered a normal part of development, stressors remain central as a potential threat to the well-being and healthy development of children into adolescents. A number of models may be relevant in explaining the association between stress and different negative psychological outcomes through the life span, for instance diathesis-stress models and differential sensitivity models [11]. Models of cumulative and simultaneous events are central for the present research when individuals experience major stressful events or transitions given the nature of adolescent development (e.g. academic demands or change in social relationships) either in close sequence (cumulatively) or simultaneously, they are more likely to have negative behavioural and emotional outcomes as a result of the confluence of events [10-11]. Cumulative events may also be characterized by increasing numbers of stressful events that occur for adolescents commensurate with changes in peer groups, friendships, parental relationships, and school demands. Coping resources may be overwhelmed by the experience of multiple changes in close proximity, which lead to negative health outcomes. In essence, the individual's assessments of the importance of the stressful events and their timing, and whether the event is controllable or not are all factors affecting whether stressful events impact negative health outcomes [11].

\section{Sample Design}

\section{METHODOLOGY}

This research was undertaken among adolescents in South Goa. The state of Goa being small has only two districts, North and South. The present study was carried out only in the Southern district. The district is further divided into five talukas, which are further divided into villages, each village is then divided into waddos. The five talukas are Canacona, Mormugao, Quepem, Salcete, Sanguem and has a total of 163 villages.

The population for this research included individuals in the age range of 10 to 19 years thus, confirming to World Health Organization (1997) standards as to the period of adolescence. The criteria for inclusion were that of any individual who was within the age range of 10 to 19 years and who had a working knowledge of English as the standardized questionnaires used in the research were in English.

A questionnaire survey was adopted for this research. Both descriptive and analytical approach was used for the study. For the collection of data, a stratified sampling technique was used. In the first phase a list of all the talukas and the villages of each taluka was obtained. Based on the number of villages, from each taluka $50 \%$ of the villages were selected to obtain data. The researchers choose a representative sample of villages from each taluka. A total sample of 205 respondents of which 99 male and 106 female respondents were used in this research. 


\section{Tools Used}

In the attempt to study the extent of stress experienced by adolescents the following psychological tests were used:

1. Personal data questionnaire

2. Life Stressors and Social Resources Inventory (LISRES- Youth) [12]

\section{Procedure}

A questionnaire survey was adopted for this research. For the collection of data, a stratified sampling technique was used. In the first phase a list of all the talukas and the villages of each taluka was obtained. Based on the number of villages, from each taluka $50 \%$ of the villages were selected to obtain data. The researchers choose a representative sample of villages from each taluka. The next step involved contacting higher secondary schools and colleges in the area and after obtaining permission for the respective authorities, the questionnaires were administered.

\section{RESULTS AND DISCUSSION}

\section{Hypothesis}

There will be a significant difference in the scores of the sub-scales of LISRES-Y among adolescents with respect to their gender.

Table 1 - Mean scores, SD and t-value of the LISRES-Y scale in terms of gender

\begin{tabular}{|c|c|c|c|c|c|c|}
\hline Dimension & Gender & Mean & T-score & Interpretation & SD & t-value \\
\hline \multirow[t]{2}{*}{ Physical Health } & Male $(n=99)$ & 1.33 & 44 & Somewhat below average & 2.08 & \multirow[t]{2}{*}{0.585} \\
\hline & Female $(n=106)$ & 1.54 & 49 & Average & 1.74 & \\
\hline \multirow{2}{*}{$\begin{array}{l}\text { Home and } \\
\text { Money }\end{array}$} & Male $(n=99)$ & 7.80 & 53 & Average & 5.72 & \multirow[t]{2}{*}{0.941} \\
\hline & Female $(n=106)$ & 8.55 & 55 & Somewhat above average & 5.34 & \\
\hline \multirow[t]{2}{*}{ Parents Stressor } & Male $(n=99)$ & 8.86 & 47 & Average & 5.19 & \multirow[t]{2}{*}{0.858} \\
\hline & Female $(n=106)$ & 8.19 & 45 & Somewhat below average & 5.08 & \\
\hline \multirow{2}{*}{ Siblings Stressor } & Male $(\mathrm{n}=99)$ & 8.38 & 45 & Somewhat below average & 5.60 & \multirow[t]{2}{*}{0.038} \\
\hline & Female $(n=106)$ & 8.23 & 45 & Somewhat below average & 6.00 & \\
\hline \multirow{2}{*}{$\begin{array}{l}\text { Extended } \\
\text { Family Stressor }\end{array}$} & Male $(n=99)$ & 5.34 & 51 & Average & 4.23 & \multirow[t]{2}{*}{0.949} \\
\hline & Female $(n=106)$ & 4.77 & 51 & Average & 4.14 & \\
\hline \multirow[t]{2}{*}{ School Stressor } & Male $(n=99)$ & 12.28 & 48 & Average & 7.62 & \multirow[t]{2}{*}{$6.49^{* *}$} \\
\hline & Female $(n=106)$ & 9.71 & 45 & Average & 6.85 & \\
\hline \multirow[t]{2}{*}{ Friends Stressor } & Male $(n=99)$ & 6.54 & 53 & Average & 4.27 & \multirow[t]{2}{*}{$5.11^{* *}$} \\
\hline & Female $(n=106)$ & 5.22 & 47 & Average & 4.14 & \\
\hline \multirow{2}{*}{$\begin{array}{l}\text { Boyfriend/ } \\
\text { Girlfriend }\end{array}$} & Male $(\mathrm{n}=99)$ & 1.98 & 40 & Well below average & 3.87 & \multirow[t]{2}{*}{0.092} \\
\hline & Female $(n=106)$ & 2.15 & 42 & Somewhat below average & 4.18 & \\
\hline \multirow{2}{*}{$\begin{array}{l}\text { Negative Life } \\
\text { Events }\end{array}$} & Male $(n=99)$ & 6.46 & 50 & Average & 5.27 & \multirow[t]{2}{*}{0.009} \\
\hline & Female $(n=106)$ & 6.54 & 53 & Average & 6.18 & \\
\hline
\end{tabular}

**Significant at the 0.01 level (2-tailed)

Table 1 indicates the mean scores, SD and t-value of the LISRES-Y scale in terms of gender. The total sample consisted of 99 male adolescent respondents and 106 female adolescent respondents, across the age groups from 10 to 19 years. Gender is an important biological determinant of vulnerability to psychosocial stress. The prevalence of depression in women is approximately twice that of men [12-14]. Adolescence marks a period of vast physical and mental changes and the emergence of many sex differences, including a female-biased prevalence of depression [15-17]. Significant stress exposure during adolescence is particularly associated with emergence of the increased prevalence of depression in females [15, 18-19] suggesting that females may be more susceptible to stress-induced depression than men [20-21]. 
Middle adolescence, which spans the ages of 13 to 17 [22], is a developmental period marked by the emergence and escalation of risk behaviour, including substance use, unsafe sexual behaviour and delinquency [23-24]. Although some degree of risk taking is considered developmentally appropriate, a subset of youth will experience serious negative consequences or progress to more problematic involvement in risk behaviour, increasing their risk of morbidity and mortality over the course of adolescence and adulthood $[23,25]$.

Gender is one factor that may influence engagement in risk behaviour in the context of affective distress. Moreover, the influence of gender may be particularly salient in adolescence given the increased frequency of psychological stress experienced during this developmental period [26-28]. Although boys and girls report comparable subjective stress levels during adolescence [29], evidence suggests that there may be important gender differences in response to stress. For instance, adolescent girls' response to stress is characterized by negative self-evaluation, rumination, and withdrawal [16; 30-31], whereas adolescent boys' response to stress most frequently takes the form of risk behaviour such as substance use, delinquency, and disagreeable, aggressive or antagonistic behaviour [16, 33]. In other words, adolescent girls seem to be more internalizing when experiencing stress, whereas adolescent boys become disinhibited.

The present study indicates that there were no significant differences in terms of gender except in terms of school and due to friends. Male adolescent children experienced school to be more stressful as compared to their female counterparts, with a mean score of 12.28 and 9.71 respectively. The raw score when converted to the T- score, males obtained a T- score of 48 and females a T- score of 45 . Both the scores were interpreted as average stress. The t-value was calculated to be 6.499 which was significant at 0.01 level of significance. Similarly, males reported more stress due to their friends as compared to females with a mean score of 6.54 and 5.22 respectively. The converted $\mathrm{T}$ - score was 53 and 47 respectively for male sand females respectively. The calculated t-value was 5.11 which was significant at 0.01 level of significance. Indicating that though the $\mathrm{T}$ - score can be interpreted as average, there were significant gender differences.

In terms of the other dimensions of the LISRES-Y scale no significant differences were found between genders. Nonetheless, at second glance it is clear that the myth of healthy adolescents cannot be sustained and that this age group, too, is characterized by specific health problems [34-35]. This is surprising, since it is precisely in the period of adolescence that the health-related relationship between the genders undergoes a marked change [36] while boys are the "weaker sex" in health terms up to puberty, this situation is reversed in adolescence. From puberty onwards, girls are more dissatisfied with their health and take up medical care more frequently. In addition, gender specific health profiles become more clear-cut: while girls suffer more frequently from psychosomatic complaints and emotional disturbances, for boys the main health problems are injuries caused by traffic accidents [37]. In the present research adolescent girls had more stress due to their physical health with a mean score of 1.54 and a T- score of 49 which is interpreted as average. Males had a mean score of 1.33 and a T- score of 44 which is interpreted as somewhat below average. The t-value was .585 which was not statistically significant.

With regard to the dimension of home and money since males and females are raised differently by their parents [38], gender roles may affect the saving and spending behaviours of male and female teenagers. Parents are usually stricter with daughters than sons. Daughters are more expected to take on household chores than sons [39]. Edwards and others [40] indicate that daughters were more open with their parents about their spending behaviours, more dependent on their parents for support, and more likely to talk with their parents about their own financial situations. In the present sample, female respondents experienced slightly higher amounts of stress with a mean score of 8.55 and a SD score of 7.80 . The raw scores are converted to 55 and 53 for female and male respondents, wherein female scores are interpreted as somewhat above average and male scores as average. The t-value was calculated to be .941 which indicates that statistically there was no difference between the groups.

Similarly, adolescent girls reported more stress in their romantic relationships with boys, with a mean score of 2.15 as compared to males with a mean score of 1.98 . The raw scores when converted to $\mathrm{T}$ - scores indicate that females obtained a $\mathrm{T}$ - score of 42 which can be interpreted as somewhat below average and males obtained a T- score of 40 which can be interpreted as well below average. Indicating that male adolescents were not stressed or affected by being in a relationship. The calculated t-value was .092 which was not statistically significant. Child rearing practices differ in the case of boys and girls. Girls are granted limited 
freedom and independence by their parents, especially in the case of romantic relationships. Due to more restrictions placed on the adolescent girls, they also experience more pressure culminating in higher levels of stress.

During adolescents, young people are experiencing tremendous physical, intellectual, social and emotional growth. This growth includes the physical growth related to puberty as well as a range of psychosocial changes associated with developing an increasingly refined identity; discovering individual talents, interests, and skills; forming meaningful peer and intimate relationships; and taking responsibility for more independent and adult decisions about risks, health, and the future [41]. Although this exciting period of development is characterized by exploration, discovery, and rapidly expanding capacities, it is also accompanied by a number of factors that make people particularly vulnerable. Exposure to negative life events represents one pathway to risk for adolescents. A large number of studies support the relationship between negative life events and internalizing symptoms such as depression and anxiety [42-44], while an equally large number of studies support the relationship between negative life events and externalizing symptoms related to anger, delinquency, and substance abuse [45-47]. Adolescent girls experienced negative life events and their effects more frequently and intensely than did boys. Numerous studies have described girls experiencing a comparatively higher number of cumulative negative life events than boys. Girls consistently experienced negative life events more frequently than boys, these findings remain stable throughout adolescent development. While girls are more susceptible to the emotional influences of NLEs, they also tend to outperform boys academically, are less likely than boys to engage in delinquency. In the present research, in accordance with other research mentioned above, girls experienced slightly more stress due to negative life events, with a mean score of 6.54 , and boys obtained a mean score of 6.46 . The converted score was 50 and 53 for both boys and girls respectively both of which can be interpreted as average.

A family and its members continue to provide valuable role models for a range of behaviours, including effective communication, relationship skills, and socially acceptable behaviours. adolescents and their families have some ups and downs during the adolescent years, but things usually improve by late adolescence as children become more mature. For adolescents, parents and families are a source of care and emotional support. However, sometimes the family and the extended family tend to be a source of stress to the adolescent. In the present research, males experienced more stress from the family in the dimensions of parental stress, sibling stress and extended family as compared to females. Males obtained a mean score of 8.86 with regard to parents as a source of stress to them, whereas females obtained a score of 8.19. The Tscore was 47 and 45 which can be interpreted as average and somewhat below average for males and females respectively. In terms of siblings as a source of stress, males obtained a mean score of 8.38 and females, a marginally lower mean score of 8.23 , with a T- score of 45 each which can be interpreted as somewhat below average for both males and females. Extended family causes males to experience more stress with a mean score of 5.34 and for females a score of 4.77 the $\mathrm{T}$ - score of both was the same of 51 which can be interpreted as average for both males and females. The $t$-value was not statistically significant in all the three dimensions.

\section{Limitations}

An objective critical insight into the research conducted has brought out the following limitations:-

1. The present research was conducted mostly on college adolescents, though an attempt was made to obtain data from adolescents who were not studying, this was not equally distributed.

2. The study was conducted only among educated adolescents and could not reach out to the general masses given the complexity of the administered questionnaires and the obvious requirement of literacy to complete the same.

3. Only the questionnaire method was used, due to paucity of time and non-availability of funds the researchers were unable to conduct any in-depth interview or personal interaction with the subjects on each of the stressors.

4. Therefore, the data obtained from the adolescents, is based on their self-assessment and the rate of socially desirable responses may have had its impact on the data so obtained. 


\section{CONCLUSION}

In summary, a perusal of Table I indicates that overall scores when converted to T- scores indicate that the adolescents in the present sample obtained slightly different scores in all the dimensions. Home and money caused adolescents the most amount of stress with an average and a somewhat average score for males and females. This was followed by negative life events, extended family, school, and friends with an average score. The remaining dimensions of physical health, parents, siblings, boyfriend and girlfriend obtained a somewhat below average score. Thus, the hypothesis which states that there will be a significant difference in the scores of the sub-scales of LISRES-Y among adolescents with respect to their gender is partially accepted since in two factors namely school stressors and friends' stressors there were significant differences between males and females and for the remaining factors, there was a difference but the difference was not statistically significant.

\section{REFERENCES}

1. Cameron G, Karabanow J. The nature and effectiveness of program models for adolescents at risk of entering the formal child protection system. Child Welfare 2003;82(4):443-74.

2. Steinberg L. Cognitive and affective development in adolescence. Trends Cogn Sci 2005;9(2):69-74.

3. Wekerle C, Waechter RL, Leung E, Leonard M. Adolescence: A window of opportunity for positive change in mental health. First Peoples Child and Family Review 2007;3(2):8-16.

4. Compas BE, Reeslund KL. Processes of risk and resilience during adolescence. Handbook of Adolescent Psychology 2009;1:561-88

5. Suldo SM, Shaunessy E, Hardesty R. Relationships among stress, coping, and mental health in highachieving high school students. Psychol Schools 2008;45(4):273-90.

6. Coleman JC, Hendry LB. The nature of adolescence. Psychology Press: New York; 1999.

7. Grant BF, Stinson FS, Dawson DA, Chou SP, Dufour MC, Compton W, Pickering RP, Kaplan K. Prevalence and co-occurrence of substance use disorders and independent mood and anxiety disorders: Results from the national epidemiologic survey on alcohol and related conditions. Arch Gen Psychiatry 2004;61(8):807-16.

8. Carter JS, Garber J, Ciesla JA, Cole DA. Modeling relations between hassles and internalizing and externalizing symptoms in adolescents: A four-year prospective study. J Abnorm Psychol 2006;115(3):428-35.

9. Charbonneau AM, Mezulis AH, Hyde JS. Stress and emotional reactivity as explanations for gender differences in adolescents' depressive symptoms. J Youth Adolesc 2009;38(8):1050-8.

10. Rudolph KD. Gender differences in emotional responses to interpersonal stress during adolescence. J Adolesc Health 2002;10:300-8.

11. Graber JA, Sontag LM. Handbook of Adolescent Psychology. Sage Publications: UK; 2009.

12. Frackiewicz EJ, Sramek JJ, Cutler NR. Gender differences in depression and antidepressant pharmacokinetics and adverse events. Ann Pharmacother 2000;34(1):80-8.

13. Noble RE. Depression in women. Metabolism 2005;54(5):49-52.

14. Solomon MB, Herman JP. Sex differences in psychopathology: of gonads, adrenals and mental illness. Physiol Behav 2009;97(2):250-8.

15. Angold A, Costello EJ, Worthman CM. Puberty and depression: the roles of age, pubertal status and pubertal timing. Psychol Med 1998;28(1):51-61.

16. Gjerde PF, Block J, Block JH. Depressive symptoms and personality during late adolescence: Gender differences in the externalization-internalization of symptom expression. J Abnorm Psychol 1988;97(4):47580.

17. Lenroot RK, Giedd JN. Sex differences in the adolescent brain. Brain Cogn 2010;72(1):46-55.

18. Becker DF, Grilo CM. Prediction of suicidality and violence in hospitalized adolescents: comparisons by sex. Can J Psychiatry 2007;52(9):572-80.

19. Conley CS, Rudolph KD. The emerging sex difference in adolescent depression: Interacting contributions of puberty and peer stress. Dev Psychopathol 2009;21(2):593-620.

20. Kudielka BM, Buske-Kirschbaum A, Hellhammer DH, Kirschbaum C. HPA axis responses to laboratory psychosocial stress in healthy elderly adults, younger adults, and children: impact of age and gender. Psychoneuroendocrinology 2004;29(1):83-98.

21. Young EA. Sex differences and the HPA axis: implications for psychiatric disease. J Gender Spec Med 1998;1(1):21-7. 
22. Fröjd SA, Nissinen ES, Pelkonen MU, Marttunen MJ, Koivisto AM, Kaltiala-Heino R. Depression and school performance in middle adolescent boys and girls. J Adolesc 2008;31(4):485-98.

23. Scott ES, Steinberg L. Adolescent development and the regulation of youth crime. The Future of Children 2008;10:15-33.

24. Smith-Khuri E, Iachan R, Scheidt PC, Overpeck MD, Gabhainn SN, Pickett W, Harel Y. A cross-national study of violence-related behaviors in adolescents. Arch Pediatr Adolesc Med 2004;158(6):539-44.

25. Brook JS, Adams RE, Balka EB, Whiteman M, Zhang C, Sugerman R. Illicit Drug Use and Risky Sexual Behavior Among African. J Genet Psychol 2004;65(2):203-20.

26. Compas BE, Wagner BM. Psychosocial stress during adolescence: Intrapersonal and interpersonal processes. Adolescent Stress: Causes and consequences 1991;67-85.

27. Ge X, Lorenz FO, Conger RD, Elder GH, Simons RL. Trajectories of stressful life events and depressive symptoms during adolescence. Dev Psychol 1994;30(4):467-76.

28. Larson R, Ham M. Stress and" storm and stress" in early adolescence: The relationship of negative events with dysphoric affect. Dev Psychol 1993;29(1):130-41.

29. Gore S, Aseltine Jr RH, Colten ME. Social structure, life stress, and depressive symptoms in a high school-age population. J Health Soc Behav 1992;1:97-113.

30. Daughters SB, Reynolds EK, MacPherson L, Kahler CW, Danielson CK, Zvolensky M, Lejuez CW. Distress tolerance and early adolescent externalizing and internalizing symptoms: The moderating role of gender and ethnicity. Behav Res Ther 2009;47(3):198-205.

31. Galaif ER, Sussman S, Chou CP, Wills TA. Longitudinal relations among depression, stress, and coping in high risk youth. J Youth Adolesc 2003;32(4):243-58.

32. Piko B. Gender differences and similarities in adolescents' ways of coping. Psychol Record 2001;51(2):223-35.

33. Achenbach TM, Edelbrock C. Child Behavior Checklist. Burlington (Vt); 1991.

34. Millstein SG, Petersen AC, Nightingale EO. Promoting the health of adolescents: New directions for the twenty-first century. Oxford University Press; 1994.

35. Schulenberg JE, Maggs JL. A developmental perspective on alcohol use and heavy drinking during adolescence and the transition to young adulthood. J Stud Alcohol 2002;14(3):54-70.

36. Kolip P. Gender Differences in Health Status During Adolescence: A Remarkable Shift. Int J Adolesc Med Health 1997;9(1):9-18.

37. Kolip P, Schmidt B, World Health Organization. Gender and health in adolescence. Copenhagen: WHO Regional Office for Europe; 1999.

38. Thorne B. Gender play: Girls and boys in school. Rutgers University Press; 1993.

39. Brusdal R, Berg L. Are parents gender neutral when financing their children's consumption?. Int J Consum Stud 2010;34(1):3-10.

40. Edwards R, Allen MW, Hayhoe CR. Financial attitudes and family communication about students' finances: The role of sex differences. Commun Reports 2007;20(2):90-100.

41. Steinberg L. Cognitive and affective development in adolescence. Trends Cogn Sci 2005;9(2):69-74.

42. Bouma EM, Ormel J, Verhulst FC, Oldehinkel AJ. Stressful life events and depressive problems in early adolescent boys and girls: The influence of parental depression, temperament and family environment. J Affect Disord 2008;105(1):185-93.

43. Franko DL, Striegel-Moore RH, Brown KM, Barton BA, McMAHON RP, Schreiber GB, Crawford PB, Daniels SR. Expanding our understanding of the relationship between negative life events and depressive symptoms in black and white adolescent girls. Psychol Med 2004;34(7):1319-30.

44. Garber J, Flynn C. Predictors of depressive cognitions in young adolescents. Cogn Ther Res 2001;25(4):35376.

45. Levers-Landis CE, Greenley RN, Burant C, Borawski E. Cognitive social maturity, life change events, and health risk behaviors among adolescents: Development of a structural equation model. J Clin Psychol Med Settings 2006;13(2):107-16.

46. Ireland TO, Smith CA, Thornberry TP. Developmental issues in the impact of child maltreatment on later delinquency and drug use. Criminology 2002;40(2):359-400.

47. Allwood MA, Baetz C, DeMarco S, Bell DJ. Depressive symptoms, including lack of future orientation, as mediators in the relationship between adverse life events and delinquent behaviors. J Child Adolesc Trauma 2012;5(2):114-28. 